\title{
FLIPI-2 Score 0, Low Risk
}

National Cancer Institute

\section{Source}

National Cancer Institute. FLIPI-2 Score 0, Low Risk. NCI Thesaurus. Code C137659.

A score indicating that a patient has 0 risk factors associated with follicular lymphoma and is considered in the low risk group. 